\title{
Gene Expression of Stromelysin and Aggrecan in Osteoarthritic Cartilage
}

\author{
J ohannes Stöve ${ }^{a}$ Christina Gerlach ${ }^{b}$ Klaus Huch ${ }^{b}$ Klaus Peter Günther \\ Rolf Brennerb Wolfhart Puhl ${ }^{b}$ Hanns-Peter Scharfa \\ aDepartment of Orthopaedic Surgery, Faculty of Clinical Medicine, University of Heidelberg, Mannheim, \\ bDepartment of Orthopaedics (RKU), University of UIm, UIm, and 'Department of Orthopaedics, \\ University of Dresden, Dresden, Germany
}

\author{
Key Words \\ Osteoarthritis - Cartilage - Stromelysin · Aggrecan - Gene \\ expression
}

\begin{abstract}
Objective: To analyze cartilage gene expression of patients with osteoarthritis (OA) in correlation with radiographic and histological findings. Materials and Methods: Twenty-one patients with OA of the knee admitted for total knee replacement were analyzed clinically and radiographically by the Kellgren and Lawrence system. During surgery, cartilage samples from the medial and lateral condyles and tibial plateaus were harvested separately. Specimens were analyzed histologically (Mankin score) and total RNA was extracted directly from cartilage tissue. Steady state levels of stromelysin (MMP-3), aggrecan (AGG) and the house-keeping gene $\beta$-actin were measured using quantitative PCR. Results: Histology of medial and lateral knee compartments corresponded to radiographic changes (Spearman correlation coefficient: $r=0.7(p<0.01))$. There was a positive correlation between MMP-3 and AGG gene expression $(r=0.4$; $<<$ 0.01 ). We found considerable variation of expression levels of MMP-3 and AGG and no correlation of gene expression with histological or radiographic scoring. Conclusion: The positive correlation between AGG and
\end{abstract}

\begin{tabular}{ll}
\hline KARGER & (c) 2002 S. Karger AG, Basel \\
Fax +4161306 1234 & $1015-2008 / 01 / 0696-0333 \$ 17.50 / 0$ \\
$\begin{array}{l}\text { E-Mail karger@karger.ch } \\
\text { www.karger.com }\end{array}$ & $\begin{array}{l}\text { Accessible online at: } \\
\text { www.karger.com/journals/pat }\end{array}$
\end{tabular}

MMP-3 suggests a common regulation of anabolic and catabolic metabolism. There was no simple dependency between gene expression and histological and radiological findings in cartilage.

Copyright $\odot 2002$ S. Karger AG, Basel

\section{Introduction}

Osteoarthritic cartilage degeneration is characterized by a loss of proteoglycans from the cartilage extracellular matrix. The progressive destruction of cartilage in osteoarthritis $(\mathrm{OA})$ is attributed to an elevation of matrixdegrading enzymes originating from chondrocytes and synoviocytes [1]. Several biochemical studies have shown an enhanced synthesis of proteoglycans in OA cartilage at least at early stages of the disease [2,3]. Thus, the net loss of matrix components has been attributed to an enhanced catabolism rather than a lack of synthesis [4, 5]. More recent studies could show that the hyperactivity of condrocytes was restricted to the middle and deeper zones of OA cartilage [6]. During cartilage degeneration, stromely$\sin$ (MMP-3; matrix metalloproteinase-3) is thought to be a major enzyme targeting several matrix components including aggrecan (AGG) [7]. AGG represents the major proteoglycan of articular cartilage providing the osmotic swelling capacity and thus elasticity [8]. The analysis of 
Table 1. Patient characteristics

\begin{tabular}{|c|c|c|c|c|c|c|}
\hline \multirow{2}{*}{$\begin{array}{l}\text { Patient } \\
\text { No. }\end{array}$} & \multirow[t]{2}{*}{ Sex } & \multirow{2}{*}{$\begin{array}{l}\text { Age } \\
\text { years }\end{array}$} & \multirow{2}{*}{$\begin{array}{l}\text { Limb } \\
\text { alignment }\end{array}$} & \multirow[t]{2}{*}{ LOA/GOA } & \multicolumn{2}{|c|}{ Gene expression } \\
\hline & & & & & stromelysin & $n$ aggrecan \\
\hline 1 & female & 77 & $185^{\circ}$ & LOA & 4.11 & 0.05 \\
\hline 2 & female & 75 & $182^{\circ}$ & LOA & 17.39 & 0.01 \\
\hline 3 & male & 59 & $181^{\circ}$ & LOA & 2.76 & 2.88 \\
\hline 4 & male & 48 & $171^{\circ}$ & LOA & 0.61 & 0.08 \\
\hline 5 & female & 68 & $175^{\circ}$ & GOA & 2.69 & 0.01 \\
\hline 6 & male & 70 & $180^{\circ}$ & LOA & 0.10 & 0.02 \\
\hline 7 & male & 65 & $182^{\circ}$ & LOA & 0.20 & 0.08 \\
\hline 8 & male & 73 & $186^{\circ}$ & GOA & 0.84 & 2.50 \\
\hline 9 & male & 57 & $184^{\circ}$ & GOA & 0.79 & 4.44 \\
\hline 10 & female & 54 & $175^{\circ}$ & LOA & 1.67 & 6.17 \\
\hline 11 & male & 75 & $166^{\circ}$ & LOA & 3.86 & 2.03 \\
\hline 12 & female & 69 & $184^{\circ}$ & LOA & 2.63 & 0.87 \\
\hline 13 & female & 71 & $182^{\circ}$ & GOA & 63.15 & 1.15 \\
\hline 14 & female & 78 & $180^{\circ}$ & LOA & 56.35 & 210.11 \\
\hline 15 & female & 75 & $168^{\circ}$ & GOA & 1.91 & 1.17 \\
\hline 16 & female & 64 & $176^{\circ}$ & GOA & 4.36 & 0.15 \\
\hline 17 & female & 81 & $183^{\circ}$ & GOA & 41.70 & 0.68 \\
\hline 18 & female & 70 & $142^{\circ}$ & LOA & 2.20 & 2.38 \\
\hline 19 & female & 76 & $184^{\circ}$ & GOA & 5.75 & 11.0 \\
\hline 20 & female & 70 & $185^{\circ}$ & GOA & 149.35 & 41.84 \\
\hline 21 & female & 81 & $158^{\circ}$ & LOA & 127.56 & 55.72 \\
\hline
\end{tabular}

Axis of the lower extremity was considered as varus limb alignment at an angle of $>174^{\circ}$ and as valgus limb alignment at $<174^{\circ}$. Mean levels of gene expression of MMP-3 and AGG (medium and lateral compartments) are given as relative expression of $\beta$-actin (\%). LOA = Localized OA; GOA = generalized OA.

AGG and MMP-3 expression in cartilage should give more insight into the degradation process during the course of OA.

In imaging techniques, like radiographic and magnetic resonance imaging, the degeneration of OA mainly appears as a rather monotonous process. On the other hand, clinical and biochemical or more recently molecular biological tools usually yield an inhomogeneous appearance of cartilage tissue [9-11], which makes a correlation among them difficult to establish. Up to now, it remains unclear which parameters will serve as a good monitor of OA progression. Gene expression analysis might help to obtain insight into the regulation of cartilage metabolism. However, up to now no study has tried to correlate radiological and histological findings of $\mathrm{OA}$ with cartilage metabolism at a molecular level. The aim of our study was to analyze the appearance of OA at a clinical, radiological and histological level in order to correlate these findings with the gene expression of AGG and MMP-3. Another purpose was to investigate whether different clinical subsets of OA, like localized and generalized OA, show differ- ences not only clinically but also at the gene expression level. While localized OA is often associated with mechanical factors, in generalized OA, metabolic or genetic defects might play a major role $[12,13]$.

\section{Material and Methods}

Fourteen female and seven male patients with OA of the knee admitted for total knee replacement have been included in the study after signing the informed consent form. The study was approved by the Ethics Committee of the University of Ulm. Patient characteristics are given in table 1 . The average age was 69.9 years (range: $48-81$ years, median 71 years). Anteroposterior (AP) weight bearing x-rays of both knees in extension and a lateral view in 40 degrees of flexion were obtained. Limb alignment was analyzed for varus/valgus deformity by measuring the lateral angle of the femur and tibia shaft axis. In addition to the x-rays of the affected joint, we obtained bilateral dorsovolar hand radiographs. Preoperative radiographs were graded according to the classification of Kellgren and Lawrence (K\&L) [14]. Generalized OA (GOA) was diagnosed if two separate joint-groups in the hands in addition to the knee joint showed radiographic OA [15]. Proximal/distal interphalangeal (PIP/DIP) joints and carpometacarpal $(\mathrm{CMC})$ joints were recorded as separate joint regions. 
The definition of GOA required involvement of at least 2 DIP or PIP joints and at least $1 \mathrm{CMC}$ joint in addition to an OA knee joint.

During surgery, cartilage samples of the medial and lateral knee compartments (condyles and tibial plateaus) were harvested separately. For histological analysis a full-thickness section of the tibial plateau of the medial and lateral sides with subchondral bone was fixed in $4 \%$ paraformaldehyde. All samples were stained with hematoxylin-eosin and safranin-O and graded using the Mankin score [11]. Total RNA was extracted directly from the cartilage tissue using the guanidinium-thiocyanate method and ultracentrifugation in cesium chloride [16, 17]. For reverse transcription we used oligo-dT primer and $1 \mu \mathrm{g}$ total RNA (cDNA kit; Roche, Mannheim, Germany). For quantification, cDNAs of MMP-3 [primer design: 5'CACTTCAGAACCTTTCCTGGCATC-3', 5'-GCTTCAGTGTTGGCTGAGTG-3' 406 bp (nucleotides 338-744)] and AGG [primer design: 5'-ACAGGTGAAGACTTTGTGGAC-3', 5'-AAGTGGTCACTCCTGGAGCAG-3' 338 bp (nucleotides 2446-2784)] were amplified in competitive PCR. Mimics, which were constructed using a commercially available kit (Clontech, San Jose, Calif., USA), were used as standards. Target gene and mimic shared the same primer binding sites. To obtain a dilution row, we performed six PCRs with different standard concentrations and an equal amount of cDNA. Samples were denatured for $2 \mathrm{~min}$ at $95^{\circ} \mathrm{C}$ and annealed for $1 \mathrm{~min}$ at $60^{\circ} \mathrm{C}$ followed by extension for $1.5 \mathrm{~min}$ at $72^{\circ} \mathrm{C}$ (PCR reagents: $10 \mathrm{~m} M$ Tris- $\mathrm{HCl}, 50 \mathrm{~m} M \mathrm{KCl}, 1.5 \mathrm{~m} M \mathrm{MgCl}_{2}, 200 \mu M$ dNTP mix, $0.4 \mu M$ primer and $2.5 \mathrm{U}$ AmpliTaq DNA polymerase (Perkin Elmer, Norwalk, Conn., USA)). DNA fragments were resolved on EtBrstained agarose gels to determine the concentration of equimolarity between target gene and standard. Band intensities were analyzed on a video imager system (Amersham-Pharmacia-Biotech, Uppsala, Sweden). The natural logarithm of the relative amounts of target and standard DNA was used to calculate the point of equimolarity (Image Master VD-Software, Pharmacia, Uppsala, Sweden). As the isolation and purification process was expected to influence the mRNA expression levels, we normalized the results to the housekeeping gene $\beta$-actin [primer design: 5'-ATCTGGCACCACACCTTCTACAATGAGCTGCG-3', 5'-CGTCATACTCCTGCTTGCTGATCCACATCTGC-3' 838 bp (nucleotides 294-1131)], which was estimated in the same way.

\section{Statistical Analysis}

Data are expressed as mean and standard error of the mean (SEM). The Mann-Whitney U-Wilcoxon Rank Sum Test was used to compare groups of evaluated parameters from medial and lateral knee compartment and the Spearman's correlation coefficient was applied to calculate the correlation between different evaluated parameters. Values of $p<0.05$ were considered significant.

\section{Results}

\section{Radiographic Analysis}

All patients had a gonarthrosis of medial and lateral compartment (bilateral gonarthrosis). Nine patients had a generalized OA and 12 had a localized OA.

Five patients had valgus gonarthrosis with a higher score according to K\&L classification in the lateral knee compartment. Two had a radiographically mild varus axis

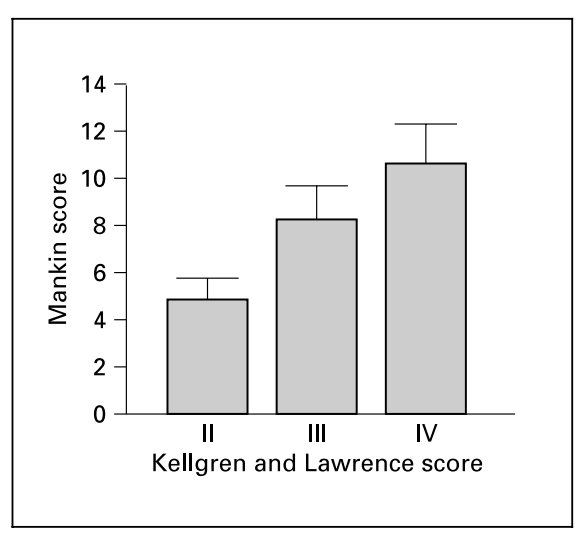

Fig. 1. Histological grading of medial and lateral compartment of different radiological grades. There were statistically significant differences between all K\&L scores $(p<$ $0.01)$.

with a grade III degradation in the medial and lateral compartment according to K\&L. All others showed a varus gonarthrosis with a mechanically loaded medial knee compartment and a grade III-IV destruction according to the K\&L classification. The lateral compartments in the latter patients were classified as grade II-III destruction.

\section{Histology}

Histological samples of medial and lateral tibia plateaus showed degenerative lesions expected from the radiographic degree of degradation. The Mankin score of different $K \& \mathrm{~L}$ grades is shown in figure 1. Histology and radiology revealed a distinct positive correlation of $\mathrm{r}=$ $0.75(\mathrm{p}<0.001)$.

\section{Gene Expression}

The mRNA expression level varied considerably even after correction on the housekeeping gene $\beta$-actin. Using $\beta$-actin not only as a housekeeping gene but also as an internal control of our RT-PCR method, we looked for the intraindividual expression level between the medial and lateral compartments. The expression level of $\beta$-actin of the medial and lateral compartments varied on average 2.5 -fold $( \pm 0.3)$.

The expression level of MMP-3 mRNA of the more severely damaged compartments showed $33.1 \pm 15.3 \%$ of $\beta$-actin expression. The corresponding results of MMP3 from the less severely damaged compartments were 13.6 $\pm 6.4 \%$ of the $\beta$-actin expression. AGG even showed a higher variability of expression: for the more severely 


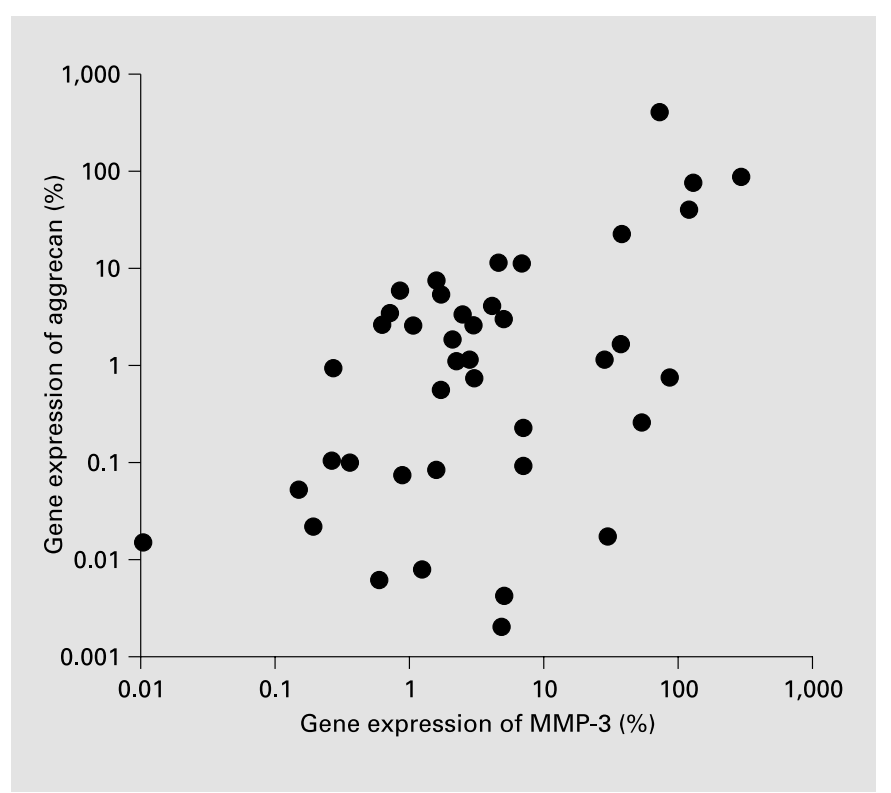

Fig. 2. Correlation of aggrecan and MMP-3 gene expression $(\mathrm{r}=$ $0.41)(p<0.01)$. Values are given in percentage of $\beta$-actin mRNA expression.

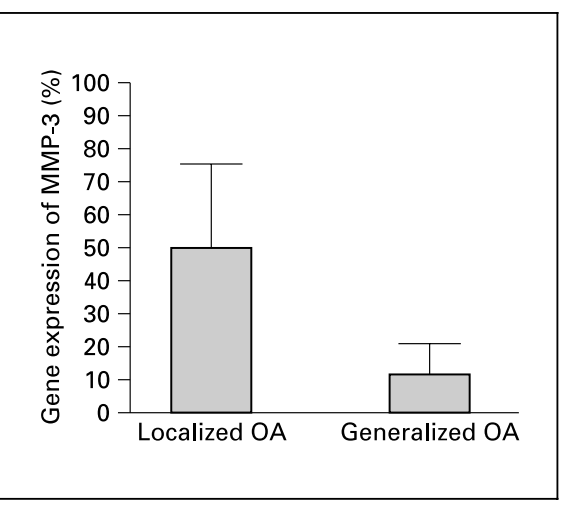

Fig. 3. Expression of MMP-3 (mean and SEM) of more severely damaged compartments (out of medial and lateral compartments) of patients with localized and generalized OA. Values are given as percentages of $\beta$-actin mRNA expression $(\mathrm{p}=0.05)$.

damaged compartments with $26.3 \pm 19 \%$ of $\beta$-actin expression; expression level for less severely damaged compartments was $6.4 \pm 3.5 \%$.

There was a positive correlation $(r=0.41)$ of MMP-3 expression and AGG expression ( $p<0.01)$ (fig. 2). However, we observed no correlation between the $\mathrm{K} \& \mathrm{~L}$ score and MMP-3 or AGG expression level, respectively. Neither could we detect any correlation between the Mankin score and expression level of MMP-3 and AGG. The distribution of MMP-3 and AGG expression of different Mankin grades is shown in figure 3.

\section{Analysis of Localized $O A$ and Generalized $O A$}

Mankin scores of localized OA (LOA) were $8.58 \pm 0.4$ points for the more severely and $6.4 \pm 0.5$ points for the less severely damaged compartment. Corresponding Mankin scores for GOA patients were $10.94 \pm 0.7$ and $7.78 \pm 0.9$ points. Patients with GOA showed an expression of $11.3 \pm 9.6 \%$ for MMP-3 and $2.06 \pm 1.16 \%$ for AGG in the more severely damaged compartment. In LOA patients we found an expression of $49.4 \pm 25.2 \%$ for MMP-3 and $44.4 \pm 32.9 \%$ for AGG. The corresponding results for the less severely damaged compartment were $6.92 \pm 3.9$ and $2.42 \pm 1.16 \%$ for GOA and $18.5 \pm 10.7$ and $9.44 \pm 5.8 \%$ for LOA patients. The difference of MMP-3 expression between LOA and GOA patients in the more severely damaged compartment (fig. 3) was marginally significant at an $\alpha$-level of $p=0.05$.

\section{Discussion}

The aim of this study was to examine OA with different analytical tools and to investigate whether there is a correlation between them. We found a positive correlation of radiographic features and histological grading in patients with mid- to late-stage OA of the knee (fig. 1). Although we could not find any correlation between radiographic or histological parameters and AGG or MMP-3 gene expression, we found a positive correlation between overall gene expression of AGG and MMP-3 (fig. 2).

In our cartilage samples we expected a correlation of histological and radiographic scores. Both scores evaluate parameters which reflect the monotonous degradation of cartilage. Although OA is characterized histologically by an inhomogeneous loss of cartilage throughout the joint, we found a distinct correlation between the K\&L score and the Mankin score in our samples. Previous studies could show a correlation of degenerative changes of cartilage in magnetic resonance imaging and histology [18].

The positive correlation of AGG and MMP-3 expression in our patients is consistent with the hypothesis that during the course of OA both the anabolic and catabolic cascade is commonly regulated [4-6, 19]. The current hypothesis is that articular chondrocytes normally pro- 
duce balanced amounts of degradative metabolites like MMPs and their inhibitors, TIMPs, and anabolic metabolites like AGG [20]. In mid stages of the disease process there is an upregulation of AGG and collagen type II [21, 22]. However, there are zonal differences in metabolic activity, and chondrocytes originating from the upper zone show suppressed activity [6].

The high variability of gene expression in our study is in agreement with previous reports which found a high variation of AGG expression in cartilage [23] and even a higher variability of COMP expression in cartilage of OA and rheumatoid arthritis [24]. Others [25] showed less variability of expression of small proteoglycans in OA tissue. However, a clinical or radiographic evaluation is missing in those latter studies. Our results suggest that gene expression is not simply correlated with radiographic and histological parameters. Whether the variability in mRNA expression truly reflects an underlying individual variation or different OA etiologies remains to be established.

Our aim was not to compare normal and OA cartilage but to analyze the metabolism of different degradation states and subsets of OA. To start with some of these problems, we set up two OA entities which are most likely to have a different underlying predisposition. Patients from LOA and GOA groups did not differ in respect to age, sex and metabolic diseases. We found a different expression level of MMP-3 in the more severely damaged knee compartment between both groups at marginal significance $(p=0.05)$ (fig. 3). However, we found a different Mankin score in patients with LOA and GOA which might have influenced MMP-3 expression as well. Only very few studies investigated differences between patients with a localized and generalized subset of OA which support the hypothesis that GOA is a distinct subset of OA [26-28]. Dequeker et al. [26] found an elevated insulin-like growth factor and transforming growth factor in cortical bone in patients with GOA. Naito et al. [27] concluded that an elevated plasma level of MMP-3 in GOA patients might be an indicator of whole joint degeneration.

The low cell numbers of cartilage tissue led us to use quantitative PCR for gene expression analysis. The most difficult problem in dealing with OA cartilage is the heterogeneity of samples. In comparison to in situ hybridization, in which the expression can be correlated to the grade of degradation, in quantitative RT-PCR a pooled sample is analyzed [6]. The high variability of gene expression, especially some very high and low levels, requires careful interpretation of the data. Besides possible confounding clinical variables which we did not control for, methodological aspects might have influenced the high variability. Therefore we looked for the intraindividual variation of $\beta$-actin which is expected to be relatively stably expressed in the medial and lateral compartment in a single patient. $\beta$-Actin, in contrast to MMP-3 and AGG, showed only little variation inter- and intraindividually, suggesting the appropriateness of the used quantitative PCR method.

In conclusion, we have shown a high variability of gene expression in OA cartilage samples. Although we found a positive correlation of anabolic and catabolic metabolites indicating a common regulation, there was no correlation with radiographic or histological features.

\section{Acknowledgement}

This study was supported by a grant from the University of Ulm to J.S. (No. 325 417).

\section{References}

1 Dean DD, Martel-Pelletier J, Pelletier JP, Howell DS, Woessner JF Jr: Evidence for metalloproteinase and metalloproteinase inhibitor imbalance in human osteoarthritic cartilage. J Clin Invest 1989;84:678-685.

2 Lippiello L, Hall D, Mankin HJ: Collagen synthesis in normal and osteoarthritic human cartilage. J Clin Invest 1977;59:593-600.

3 Sandy JD, Adams ME, Billingham ME, Plaas A, Muir H: In vivo and in vitro stimulation of chondrocyte biosynthetic activity in early experimental osteoarthritis. Arthritis Rheum 1984;27:388-397.
4 Mankin HJ, Johnson ME, Lippiello L: Biochemical and metabolic abnormalities in articular cartilage from osteoarthritic human hips. III. Distribution and metabolism of amino sugar-containing macromolecules. J Bone Joint Surg Am 1981;63:131-139.

5 Sweet MB, Thonar EJ, Immelman AR, Solomon L: Biochemical changes in progressive osteoarthrosis. Ann Rheum Dis 1977;36:387398.

6 Aigner T, Dudhia J: Phenotypic modulation of chondrocytes as a potential therapeutic target in osteoarthritis: A hypothesis. Ann Rheum Dis 1997;56:287-291.
7 Hasty KA, Reife RA, Kang AH, Stuart JM: The role of stromelysin in the cartilage destruction that accompanies inflammatory arthritis. Arthritis Rheum 1990;33:388-397.

8 Roughley PJ, Lee ER: Cartilage proteoglycans: Structure and potential functions. Microsc Res Tech 1994;28:385-397.

9 Freemont AJ, Hampson V, Tilman R, Goupille P, Taiwo Y, Hoyland JA: Gene expression of matrix metalloproteinases 1,3 , and 9 by chondrocytes in osteoarthritic human knee articular cartilage is zone and grade specific. Ann Rheum Dis 1997;56:542-549. 
10 Okada Y, Shinmei M, Tanaka O, Naka K, Kimura A, Nakanishi I, Bayliss MT, Iwata K, Nagase H: Localization of matrix metalloproteinase 3 (stromelysin) in osteoarthritic cartilage and synovium. Lab Invest 1992;66:680690.

11 Mankin H, Dorfman H, Lippiello L, Zarins A: Biochemical and metabolic abnormalities in articular cartilage from osteo-arthritic human hips. J Bone Jt Surg 1971;53A:523-537.

12 Cooper C, Egger P, Coggon D, Hart DJ, Masud T, Cicuttini F, Doyle DV, Spector TD: Generalized osteoarthritis in women: Pattern of joint involvement and approaches to definition for epidemiological studies. J Rheumatol 1996;23: 1938-1942

13 Kellgren JH, Moore R: Generalized osteoarthritis and Heberden nodes. Br Med J 1952;i: 181-187.

14 Kellgren JH, Lawrence JS: Radiological assessment of osteo-arthrosis. Ann Rheum Dis 1957; 16:494-502.

15 Gunther KP, Sturmer T, Sauerland S, Zeissig I, Sun Y, Kessler S, Scharf HP, Brenner H, Puh $\mathrm{W}$ : Prevalence of generalised osteoarthritis in patients with advanced hip and knee osteoarthritis: The Ulm Osteoarthritis Study. Ann Rheum Dis 1998;57:717-723.

16 Chomczynski P, Sacchi N: Single-step method of RNA isolation by acid guanidinium thiocyanate-phenol-chloroform extraction. Anal Biochem 1987;162:156-159.

17 Margerie D, Flechtenmacher J, Buttner FH Karbowski A, Puhl W, Schleyerbach R, Bartnik E: Complexity of IL-1-beta induced gene expression pattern in human articular chondrocytes. Osteoarthritis Cartilage 1997;5:129_ 138.
18 Trattnig S, Huber M, Breitenseher MJ, Trnka HJ, Rand T, Kaider A, Helbich T, Imhof H, Resnick D: Imaging articular cartilage defects with 3D fat-suppressed echo planar imaging: Comparison with conventional 3D fat-suppressed gradient echo sequence and correlation with histology. J Comput Assist Tomogr 1998; 22:8-14.

19 Poole AR, Rizkalla G, Ionescu M, Reiner A, Brooks E, Rorabeck C, Bourne R, Bogoch E: Osteoarthritis in the human knee: A dynamic process of cartilage matrix degradation, synthesis and reorganization. Agents Actions Suppl 1993;39:3-13.

20 Matyas JR, Ehlers PF, Huang D, Adams ME: The early molecular natural history of experimental osteoarthritis. I. Progressive discoordinate expression of aggrecan and type II procollagen messenger RNA in the articular cartilage of adult animals. Arthritis Rheum 1999;42: 993-1002.

21 Rizkalla G, Reiner A, Bogoch E, Poole AR: Studies of the articular cartilage proteoglycan aggrecan in health and osteoarthritis. Evidence for molecular heterogeneity and extensive molecular changes in disease. J Clin Invest 1992; 90:2268-2277.

22 Matyas JR, Adams ME, Huang D, Sandell LJ: Discoordinate gene expression of aggrecan and type II collagen in experimental osteoarthritis. Arthritis Rheum 1995;38:420-425.
23 Aigner T, Vornehm SI, Zeiler G, Dudhia J, von-der-Mark K, Bayliss MT: Suppression of cartilage matrix gene expression in upper zone chondrocytes of osteoarthritic cartilage. Arthritis Rheum 1997;40:562-569.

24 Di-Cesare PE, Fang C, Leslie MP, Della-Valle CJ, Gold JM, Tulli H, Perris R, Carlson CS: Localization and expression of cartilage oligomeric matrix protein by human rheumatoid and osteoarthritic synovium and cartilage. J Orthop Res 1999; 17:437-445.

25 Szabo-CS G, Melching LI, Roughley PJ, Glant TT: Changes in messenger RNA and protein levels of proteoglycans and link protein in human osteoarthritic cartilage samples. Arthritis Rheum 1997;40:1037-1045.

26 Dequeker J, Mohan S, Finkelman RD, Aerssens J, Baylink DJ: Generalized osteoarthritis associated with increased insulin-like growth factor types I and II and transforming growth factor beta in cortical bone from the iliac crest. Possible mechanism of increased bone density and protection against osteoporosis. Arthritis Rheum 1993;36:1702-1708.

27 Naito K, Takahashi M, Kushida K, Suzuki M, Ohishi T, Miura M, Inoue T, Nagano A: Measurement of matrix metalloproteinases (MMPs) and tissue inhibitor of metalloproteinases-1 (TIMP-1) in patients with knee osteoarthritis: Comparison with generalized osteoarthritis. Rheumatology (Oxford) 1999;38: 510-515.

28 Hopkinson ND, Powell RJ, Doherty M: Autoantibodies, immunoglobulins and $\mathrm{Gm}$ allotypes in nodal generalized osteoarthritis. $\mathrm{Br} \mathrm{J}$ Rheumatol 1992;31:605-608. 